\title{
Spatial price discrimination in the spokes model ${ }^{*}$
}

\author{
Carlo Reggiani ${ }^{\dagger}$
}

December 2012

\begin{abstract}
The spokes model allows addressing non-localised spatial competition between firms. In a spatial context firms can price discriminate using location-contingent pricing. Non-localised competition implies that neighbouring effects are not relevant to firms. This paper analyses spatial price discrimination and location choices in the spokes model. Highly asymmetric location patterns are one outcome if the number of firms is sufficiently high: in that case, one firm supplies a generally appealing product while others focus on a specific niche. Moreover, multiple equilibria arise for intermediate values of the number of firms. In this case, the location patterns do not always globally minimise the sum of transport costs: asymmetric configurations distribute more efficiently the cost between firms.
\end{abstract}

JEL code: D43, L11, L13.

Keywords: spatial price discrimination, spokes model, optimal location.

\section{Introduction}

Price discrimination is a pervasive practice in many markets: it takes place both in highly concentrated markets and in more competitive ones, in which several firms are active. Price discrimination also arises in markets strongly characterized by a spatial dimension. A feature of these markets is that competition is not necessarily

\footnotetext{
${ }^{*}$ I thank Hemant Bhargava, Anindya Bhattacharya, Bipasa Datta, Norman Ireland, Mark Lijesen, Mario Pezzino, Peter Simmons, Klaus Zauner and specially Ramon Caminal; seminar and conference participants in York, Manchester, Lecce and Ljubljana; the editors and the anonymous referees for helpful comments and discussion. The usual disclaimer applies.

${ }^{\dagger}$ School of Social Sciences, University of Manchester, Manchester M13 9PL, UK. E-mail: carlo.reggiani@manchester.ac.uk.
} 
localised: firms compete to attract a consumer not only with neighbouring firms but also with more distant ones. A number of spatial non-localised markets exist where price discrimination takes place; moreover, if location is interpreted as the space of characteristics, examples include alcoholic and soft drinks, shoes and clothing, software and many others: in all these markets, IT and marketing innovation are leading to wider and more personalised product lines as firms try to better match consumers' tastes and extract surplus from consumers in different segments.

A key strategic decision in these markets is firms' location and, hence, which segment of the market to be targeted. A very relevant question is whether firms hit on a specific niche of the market or adapt their product line in a way that makes it appealing to a wider segment of consumers, i.e. they supply a "general purpose" product line.

The spokes model (Chen and Riordan, 2007a) provides a framework to analyse markets characterized by spatial but non-localised competition between firms: the model naturally extends the Hotelling (1929) approach to the case of several segments and an arbitrary number of firms by modelling the market as a collection of spokes with a common core. Consumers can buy from whichever firm they like: if the firm is not located on their own spoke, however, either the customer or the delivering firm have to travel through the centre of the market. The spokes model is an important alternative to the circular city model (Salop, 1979) when the neighbouring effects of competition are not particularly relevant.

This paper addresses the question of what segments of the market firms target by analysing optimal location in the spokes model. The analysis shows that, in presence of price discrimination/product personalization, the equilibrium outcome can be characterized by one firm whose product line is appealing to consumers in all segments of the market; the remaining competitors target only part of their own market segment, focusing on a niche of customers with a strong preference for the products supplied by the firm. In devising the optimal location/product line patterns in the spokes model with price discrimination, it is also found that multiple equilibria arise depending on the number of firms in the market. An interesting finding is that, in that case, one of the outcomes may not globally minimise the sum of transportation costs.

The spokes model has been introduced relatively recently but has already been widely adopted. Chen and Riordan (2007a) show that the model captures Cham- 
berlin's original idea of monopolistic competition; moreover, strategic interaction between firms may lead to price increasing competition. Caminal and Claici (2007) use the model to show how the business stealing effect makes loyalty-rewarding schemes mostly pro-competitive. Chen and Riordan (2007b) illustrate the joint relevance of vertical integration and exclusive dealing in foreclosing the upstream market and increasing downstream prices. Germano (2009) and Germano and Meier (2010) adopt the model to address issues related to the bias of information in media markets. Caminal (2010) analyses the supply of content in different languages in bilingual contexts. Caminal and Granero (2012) look at the provision of variety by multi-product firms in the spokes model. Mantovani and Ruiz-Aliseda (2011) analyse cooperative innovation activity of firms producing complementary products. A unifying characteristic of the recalled literature is the focus on pricing and entry aspects of the interaction between firms. This paper is, to the best of my knowledge, the first to address the issue of location in the spokes model.

The contribution of this paper is also related to the literature on spatial price discrimination and endogenous location choice. Thisse and Vives (1988) observed that price discrimination in a spatial market is detrimental to firms' profits: firms exploit their information on consumers' locations and can match any offer made by a rival firm, unless this is lower than the cost of delivering the good. The classical paper of Lerner and Singer (1937) established that the optimal location configuration on a line is transport cost minimising. Lederer and Hurter (1986) analyse endogenous location and establish the existence of price-location equilibria in a rather general (e.g. two-dimensional product space, generic consumers' distribution) spatial duopoly. Their results confirm that the profit maximising locations chosen by firms correspond to the ones that minimise the overall transport costs afforded by firms. However, in presence of multiple equilibria, the location configuration may not be globally minimising the sum of transport costs. MacLeod, Norman and Thisse (1988) consider the price-location equilibria of an $n$-firms spatial model where the number of firms is endogenously determined by the fixed costs. Free entry might lead to either a too large or a too small number of varieties. Vogel (2011) analyses spatial price discrimination and the location of heterogeneous firms in the circle finding that more efficient firms are relatively more isolated in equilibrium. Anderson and De Palma (1988) question Lederer and Hurter's results by introducing product heterogeneity: the equilibrium location pattern minimises the overall transport costs only in pres- 
ence of homogeneous or very heterogeneous products. Konrad (2000) shows that in presence of a contest for consumers, in which firms afford sunk costs, the equilibrium locations are not minimising overall transport costs. Finally, Gupta (1992) considers sequential entry in a linear city with discriminatory pricing; his results on transport cost minimization crucially depend on the number of firms (two or three) entering in the market. As Lederer and Hurter (1986), Anderson and De Palma (1988) and Kon$\operatorname{rad}(2000)$, this paper also shows that price discrimination may not lead to location profiles that globally minimise the overall transport cost: in the spokes model the rise of inefficiency is related to the market features and structure (number of firms and segments). Moreover, differently from MacLeod, Norman and Thisse (1988) and Vogel (2011) my focus is on location and targeting of different segments of the market rather than on issues related to entry and the heterogeneity of firms.

The rest of the paper is structured as follows. Section 2 introduces the spokes model and the game played by price discriminating firms. Section 3 characterizes the outcomes of competition and provides a discussion of the results. Section 4 extends the model in several ways: Section 4.1 allows for heterogeneous production costs; Section 4.2 addresses quadratic transport costs; Section 4.3 considers a more general consumers' distribution function and Section 4.4 focuses on the case of more firms than spokes. Section 5 concludes.

\section{The spokes model with price discrimination}

The market is constituted of a set of spokes with a common core. There is a fixed number of spokes $N$ and each spoke has constant length, normalized to $l_{s}=1 / 2, s=$ $1 \ldots N$. Consumers are distributed along each spoke according to a uniform distribution function so that at each location on a spoke there are $\frac{2}{N}$ consumers. Each customer has a valuation $v$ for the good and can demand at most one unit of it. The good can be demanded from any firm on the market, unlike Chen and Riordan (2007a) setup in which consumers have preferences for only two goods. $v$ is assumed to be high enough so that the market is covered.

Every firm $i$ is assigned a spoke $i$ and can choose a location along this spoke, with $i=1 \ldots n, n \geq 2$. Consistently with Chen and Riordan (2007a) it is assumed that the number of firms does not exceed the number of spokes, i.e. $n \leq N$. The good supplied is homogeneous at the source but can be adapted to consumers' tastes as 


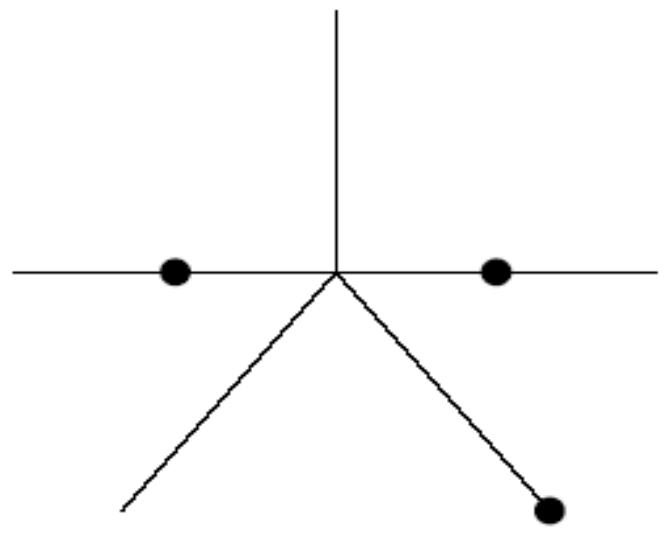

Figure 1: Spokes model with endogenous location with $n=3$ and $N=5$.

the firms deliver the product and bear the cost of the distance that separates them from the consumers. A generic firm $i$ can locate on any point of its spoke $l_{i}$ which is denoted by $y_{i}$; so that $y_{i} \in[0,1 / 2]$.

Figure 1 illustrates the spokes model in case two firms are located in the interior of their spoke while one is at the extreme. The two remaining spokes are not occupied by any firm although consumers are uniformly distributed over all the spokes.

Firms price discriminate customers according to their location over the spokes. A customer located on a spoke $s$ is identified by $x$ : consumers in $x_{s}=0$ are located at the extreme of the considered spoke while consumers at $x_{s}=1 / 2$ are exactly at the centre of the market. The distance between firm $i$, located at $y_{i}$ and the customer located at $x_{s}$ is denoted as $d\left(y_{i}, x_{s}\right)$ and it is also spoke-dependent. In particular, if the firm and the customer are both located on the $i$-th spoke, then distance can be written as:

$$
d\left(y_{i}, x_{s}\right)=\left|y_{i}-x_{s}\right| \quad s=i
$$

If the firm is located on a different spoke with respect to customer $x_{s}$ the distance is:

$$
d\left(y_{i}, x_{s}\right)=\left(\frac{1}{2}-y_{i}\right)+\left(\frac{1}{2}-x_{s}\right)=1-y_{i}-x_{s} \quad \forall s \neq i
$$

as the firms always have to travel towards the centre of the market to deliver the product to consumers located over different segments. The unit transportation cost 
is denoted by $t$; the total transport cost $T_{i s}\left(y_{i}, x_{s}\right)=t d\left(y_{i}, x_{s}\right)$ is linear in distance and captures the disutility of adapting the good to consumers tastes. Each firm faces a constant marginal cost $c$ to produce the good.

The timing of the game played by the $n \leq N$ firms:

1. Nature assigns to each of the $n$ firms a spoke $i$.

2. Location stage: each firm chooses its location $y_{i} \in[0,1 / 2]$ on its spoke;

3. Pricing stage: given the location $y_{i}$, the firm chooses the price schedule $p_{i}\left(x_{s} \mid y_{i}\right)$.

The game is solved by backward induction to identify strategies which are undominated and constitute a subgame perfect equilibrium. The following analysis closely parallels Lederer and Hurter (1986): analogies and differences will be highlighted.

\section{Results}

\subsection{The pricing stage}

Given a location profile $y=\left(y_{1} \ldots y_{n}\right)$, firms choose a price schedule: $p_{i}\left(x_{s} \mid y_{i}\right), \forall i=$ $1 \ldots n$. Consumers located at $x_{s}$ choose to buy from the firm providing the good at the lowest price. ${ }^{1}$ Naming $X$ as the set of locations over all the $N$ spokes, from the point of view of firm $i$ the market $X$ can be partitioned as follows:

$$
\begin{aligned}
& D_{i}\left(p_{i}, p_{-i}\right)=\left\{x \in X \text { s.t. } p_{i}\left(x \mid y_{i}\right)<\min \left\{p_{-i}\left(x \mid y_{-i}\right\}\right\}\right. \\
& D_{S}\left(p_{i}, p_{-i}\right)=\left\{x \in X \text { s.t. } p_{i}\left(x \mid y_{i}\right)=\min \left\{p_{-i}\left(x \mid y_{-i}\right\}\right\}\right.
\end{aligned}
$$

The set $D_{i}$ is the segment of demand served by the $i$-th firm individually while $D_{S}$ is shared with one or more rival firms. A cost-advantage (or efficient) sharing rule completes the definition of firm $i$ 's demand schedule, i.e. a function $r\left(y_{i}, p_{i}, y_{-i}, p_{-i}, x\right)$ that in case of a price tie allocates the demand to the lowest net cost producer. The profit function of firm $i$ can then be written as:

$$
\begin{aligned}
& \pi_{i}^{r}\left(y_{i}, p_{i}, y_{-i}, p_{-i}, x\right)=\frac{2}{N} \int_{D_{i}}\left[p_{i}\left(x \mid y_{i}\right)-t d\left(y_{i}, x\right)-c\right] d x \\
& +\frac{2}{N} \int_{D_{S}}\left[p_{i}\left(x \mid y_{i}\right)-t d\left(y_{i}, x\right)-c\right] r\left(y_{i}, p_{i}, y_{-i}, p_{-i}, x\right) d x
\end{aligned}
$$

\footnotetext{
${ }^{1}$ When no ambiguity is possible, the notation $x$ is used from now on instead of $x_{s}$.
} 
Consistently with Lederer and Hurter (1986), weakly dominated strategies and, hence, possible equilibria in which weakly dominated strategies are played are ruled out. This is equivalent to require:

$$
p_{i}(x \mid y) \geq c+t d\left(y_{i}, x\right) \quad \text { and } p_{i}(x \mid y) \leq v \quad \forall x \in X
$$

Proposition 1 characterizes the unique pure strategy equilibrium of the pricing stage and it is a straight generalization of Lederer-Hurter (1986) to the spokes model and $n$ firms: ${ }^{2}$

Proposition 1 Given the set of locations $y=\left(y_{1}, \ldots, y_{i}, \ldots, y_{n}\right)$, the unique equilibrium of the pricing stage is:

$$
p_{i}^{*}(x \mid y)=\max \left\{c+t d\left(y_{i}, x\right), \min \left\{c+t d\left(y_{-i}, x\right)\right\}\right\}
$$

The equilibrium price schedule is closely related to the cost structure. As a consequence of undercutting, the price at a generic location $x$ is either the firm's cost of delivering the product or, if the firm is the lowest cost provider, the cost of the firm that is the second most efficient in delivering the good. This result constitutes the foundation of the ensuing analysis of firms' location decisions.

\subsection{The location stage}

The equilibrium price schedule identified by (1) implies that the profit function for firm $i$ can be written as:

$$
\pi_{i}\left(y_{i}, p_{i}, y_{-i}, p_{-i}, x\right)=\frac{2}{N} \int_{D_{i}}\left[\min \left\{c+t d\left(y_{-i}, x\right)\right\}-\left(c+t d\left(y_{i}, x\right)\right)\right] d x
$$

The equilibrium outcome of the location stage is defined as:

$$
y_{i}^{*} \in \arg \max _{y_{i} \in X} \pi_{i}\left(y_{i}, p_{i}^{*}, y_{-i}^{*}, p_{-i}^{*}\right) \quad \forall i=1 \ldots n
$$

Consistently with Chen and Riordan (2007a), two cases are analyzed: if $n=N$ there are as many firms as spokes; if $n<N$ some spokes are not assigned to any firm.

\footnotetext{
${ }^{2}$ The proof follows Lederer and Hurter (1986), Theorem 1 and it is available upon request.
} 


\subsubsection{The $n=N$ case}

The number of firms in the market equals the number of spokes. In this context, social cost is defined as the lowest aggregate costs borne by firms to supply the good to all customers on the market. Given a vector of locations $y=\left(y_{1}, \ldots, y_{i}, \ldots y_{n}\right)$, social cost is then:

$$
S C(y)=\frac{2}{n} \int_{X} \min _{\forall i}\left\{c+t d\left(y_{i}, x\right)\right\} d x
$$

Social cost is a continuous function of $y$ over the support $X$. Following Lederer and Hurter (1986), it can be shown that the social cost function and the profits of a firm are closely related:

$$
\begin{aligned}
& \pi_{i}\left(y_{i}, p_{i}, y_{-i}, p_{-i}, x\right)=\frac{2}{n} \int_{D_{i}}\left[\min \left\{c+t d\left(y_{-i}, x\right)\right\}-\left(c+t d\left(y_{i}, x\right)\right] d x=\right. \\
= & \frac{2}{n} \int_{X} \min \left\{c+t d\left(y_{-i}, x\right)\right\} d x-\frac{2}{n} \int_{X} \min _{\forall j}\left\{c+t d\left(y_{j}, x\right)\right\} d x= \\
= & \frac{2}{n} \int_{X} \min \left\{c+t d\left(y_{-i}, x\right)\right\} d x-S C(y)
\end{aligned}
$$

The profits of firm $i$ consist of two elements. The first is positive and it is obtained in the region $D_{i}$ where the firm is the lowest cost provider: in that region, by definition, the firm concurs to determine the social cost. According to (1) the profits on $D_{i}$ are the differential between the firm's delivery cost and the second most efficient firm's cost. The other part is constituted by the rest of the market on which the firm is not the lowest cost provider and, as such, does not concur to determine the social cost; however, it does not make any profit either. Hence, profits consist of the difference, on all the market $X$, between the lowest cost rival and the social cost: in region $D_{i}$ the social cost corresponds to the firm's cost while outside $D_{i}$ it corresponds to the cost of the most efficient rival. Relation (2) leads to:

Proposition 2 In the spokes model with price discrimination and $n=N$ the vector of locations $y^{*}=\left(y_{1}^{*}, \ldots, y_{i}^{*}, \ldots y_{n}^{*}\right)$ is an equilibrium outcome if and only if:

$$
S C\left(y_{i}^{*}, y_{-i}^{*}\right) \leq S C\left(y_{i}, y_{-i}^{*}\right) \quad \forall y_{i} \in X \forall i=1 \ldots n .
$$

An implication of this result is that, in the spokes model with price discrimination and $n=N$, if the equilibrium outcome is unique then it is minimising the social cost function. The result can be interpreted as follows. The competitive pressure between 
firms drives prices down to cost; in case of a price tie, the most efficient firm wins the consumer as prescribed by the sharing rule. As the cost of the second most efficient firm is not affected by the firm's location, all that matters to the choice of location is to minimise cost over the firm's own turf; this implies that the incentives in choosing location are in line with minimising the social cost function. The result extends Lederer and Hurter (1986), Theorem 3, to the spokes model: ${ }^{3}$ under price discrimination in a spokes market structure and in presence of competition between $n$ firms, an equilibrium vector of locations minimises the social cost function.

The next result characterizes the outcomes of the game and relates them to the number of firms in the market:

Proposition 3 Price discrimination in the spokes model with $n=N$ firms leads to the following pure strategy equilibrium outcomes:

(i) for $n=2,3$ the symmetric location configuration $y_{i}^{*}=\frac{1}{4}, \forall i=1 \ldots n$ is the equilibrium outcome; no asymmetric equilibrium outcomes exist.

(ii) for $n=4,5$ the symmetric location configuration $y_{i}^{*}=\frac{1}{4}, \forall i=1 \ldots n$ and the asymmetric $y_{i}^{*}=\frac{1}{2}, y_{k}^{*}=\frac{1}{6} \forall k \neq i$ are both equilibrium outcomes .

(iii) for $n \geq 6$ the asymmetric location configuration $y_{i}^{*}=\frac{1}{2}, y_{k}^{*}=\frac{1}{6} \forall k \neq i$ is the equilibrium outcome; no symmetric outcomes exist.

The result in part (i) is consistent with the outcome of spatial price discrimination in the Hotelling model with homogeneous firms (Lerner and Singer, 1937; Kats, 1987): if $n=2$, firms locate at one half of their own spoke. This symmetric location configuration constitutes an equilibrium outcome when the market structure is not too competitive $(n \leq 5)$. The reason is that when the number of spokes (and, consequently, competitors) is relatively small a move towards the centre is not profitable; however, as the number of spokes increases $(n \geq 6)$, the gains of a small deviation that steals consumers from the competitors are multiplied sufficiently to compensate for the inframarginal losses that the firm makes on its captive market. The latter fact explains why there is no symmetric outcome in part (iii): if $n \geq 6$ the asymmetric configuration is the only equilibrium outcome. More interesting is case (ii): if the market is competitive enough $(n=4,5)$, multiple equilibrium outcomes arise. In this

\footnotetext{
${ }^{3}$ This result is at the same time a special case of Theorem 3 in Lederer-Hurter[18] as the location in the spokes model is constrained to one-dimension.
} 
case, the asymmetric location configuration is an outcome and so is the symmetric one discussed above. In the asymmetric outcome, one firm occupies the central location of the market. In response all other firms optimally choose their location at one third of their spoke. It can be shown that the central firm would have an incentive to move even further if the centre was not the boundary of its location choice. In the symmetric configuration, firms do not have enough gains on the remaining spokes to justify an unilateral deviation. In presence of multiple outcomes, it is interesting to compare the equilibria in terms of profits: in the symmetric configuration firms get $\pi_{i}\left(\frac{1}{4}, \ldots, \frac{1}{4}\right)=\frac{3 t}{8 n}$ while in the asymmetric one the firm located in the centre gets $\pi_{i}\left(\frac{1}{2}, \frac{1}{6}, \ldots, \frac{1}{6}\right)=\frac{t}{18 n}(n+5)$ while all other firms' profits are $\pi_{k}\left(\frac{1}{6}, \ldots, \frac{1}{6}, \frac{1}{2}\right)=\frac{t}{6 n}$. The comparison of the expressions for the relevant values, $n=4,5$, leads to conclude that: ${ }^{4}$

$$
\pi_{i}\left(\frac{1}{2}, \frac{1}{6}, \ldots, \frac{1}{6}\right)>\pi_{i}\left(\frac{1}{4}, \ldots, \frac{1}{4}\right)>\pi_{k}\left(\frac{1}{6}, \ldots, \frac{1}{6}, \frac{1}{2}\right)
$$

The case of $n=4,5$ firms is also interesting for the implications of multiplicity on social cost. Social cost in the symmetric configuration is $S C\left(\frac{1}{4}, \ldots, \frac{1}{4}\right)=c+\frac{1}{8} t$ while in the asymmetric one is $S C\left(\frac{1}{2}, \frac{1}{6}, \ldots, \frac{1}{6}\right)=c+\frac{n+2}{12 n} t$; hence, social cost is identical in both configurations if $n=4$ while $S C\left(\frac{1}{2}, \frac{1}{6}, \ldots, \frac{1}{6}\right)<S C\left(\frac{1}{4}, \ldots, \frac{1}{4}\right)$ if $n=5$. Although both outcomes are local minimisers, the asymmetric configuration is then the only global minimiser of the social cost: with respect to the symmetric profile, in which transport costs are shared equally between firms, a higher cost for the firm in the centre is more than compensated by the reduction on the costs bore by other firms. Lederer and Hurter (1986) also showed through an example how the equilibrium locations chosen by two firms in the space may not be globally minimising social cost; the results provided above show that an equilibrium which does not minimise globally social cost can take place even when competition is one-dimensional as in the spokes model.

\footnotetext{
${ }^{4}$ Both the symmetric and the asymmetric outcomes arise in the simultaneous location setting. However, if the location stage is sequential, only asymmetric outcomes arise. The intuition goes as follows. Any firm's best response function has at least two segments, depending on whether the firm is the closest to the centre or not. Using backward induction, best responses have to be computed for all possible scenarios up to the first firm to choose, say 1. Firm 1 has a first mover advantage and so prefers the scenario in which it is the closest firm to the centre: the centre is actually the profit maximising location and all other firms choose the optimal interior location at one third of their own spoke.
} 


\subsubsection{The $n<N$ case}

Suppose there exist more market segments than firms, i.e. the number of firms $n$ in the market is smaller than the number of spokes $N$. The unique pure strategy equilibrium of the pricing stage in Proposition 1 still applies: on the spokes occupied by one firm, the lowest cost firm serves consumers, pricing them at the cost of the second most efficient competitor; on spokes that are not occupied by any firm, a firm with a cost advantage in delivering would capture all the customers by pricing at the most efficient rival's delivered cost; if there is more than one most efficient firm, all of them price equally at the common delivered cost. The equilibrium price schedules are then given by (1).

Turning to the location stage, first it can be ruled out that any symmetric location configuration constitutes an equilibrium outcome; only then, equilibrium outcomes are characterized. The main difference with the previous case $(n=N)$ is the presence of empty spokes. The consumers on parts of the market not served by a firm do not have a strongly favourite brand available on the market (or a local supplier in the geographical interpretation); hence, all firms on the market are on even grounds when trying to attract consumers from the empty segments and have them buy their product. This feature impacts on the equilibrium outcome as no symmetric configuration is now possible.

Lemma 1 In the spokes model with price discrimination and $n<N$ firms a symmetric pure strategy equilibrium of the location stage does not exist.

The intuition for this result is the following. Suppose first that the centre, where all the spokes join, is the symmetric equilibrium location of all firms. In that case, firms obtain no profit and they have a unilateral incentive to deviate to a location internal to their own spokes. However, if the location equilibrium is a vector of points internal to the spokes, then any of the firms has an incentive to move towards the centre to undercut all competitors and serve a larger share of the market, including the empty spokes. A symmetric location, then, can not be an equilibrium outcome.

The next proposition characterizes the equilibrium configuration in the $n<N$ case.

Proposition 4 In the spokes model with price discrimination and $n<N$ firms the 
unique equilibrium location configuration is:

$$
y_{i}^{*}=\frac{1}{2} \quad y_{k}^{*}=\frac{1}{6} \quad \forall k \neq i
$$

and it is social cost minimising.

The asymmetric configuration of Proposition 3 is also an equilibrium outcome in case not all spokes are occupied, $n<N$. The intuition for the result is also similar to the $n=N$ case: no more than one firm locates in the centre of the market, otherwise all profits go to zero. So only one firm locates in the centre and serves consumers on all segments of the market. The remaining firms optimally specialize in serving only part of their own spokes. Optimal locations are independent of the number of firms and the number of spokes. Social cost is also minimised when one firm locates at the centre of the market: the total transport costs decrease with the firm location and the centre provides the limit. All other firms choose a location in the interior of their spokes and the cost minimising one coincides with the profit maximising, $y_{k}^{*}=\frac{1}{6}$.

\subsection{Discussion}

One result stands out in both of the cases analysed $(n=N$ and $n<N)$ : highly asymmetric location patterns can arise as a result of price discrimination in the spokes model. This is particularly interesting as these outcomes are obtained in a context in which firms are homogeneous and the spatial structure is symmetric. The implication is that price discriminating firms that face non-localised competition in a segmented market may locate so that one firm occupies a central spot and serves consumers on all segments of the market; all other firms narrow their focus to their own segment.

Moreover, MacLeod, Norman and Thisse (1988) propose an interpretation for spatial price discrimination in the characteristics space. In standard spatial models transportation costs are a measure of disutility and location is a product characteristic. In presence of price discrimination, instead, firms personalize and adapt their product lines to the demand expressed by buyers. Despite in the last decade relationship marketing and one-to-one marketing have become established practices, firms are not yet offering a customised product to every buyer. ${ }^{5}$ However, the diffusion of online shopping guarantees firms access to an unprecedented amount of data about their

\footnotetext{
${ }^{5}$ For example Nike or Adidas, leaders in the sports equipment sector, have product lines for most sports: online customers can personalise to some extent but can not get a fully customised product.
} 
customers: this is likely to enhance the trend towards more and more personalised products in the future. The customised product interpretation fits better businessto-business contexts: software providers, for example, compete for customers with standardised products that can be adjusted at some cost to the specific needs of the customer. In these contexts, some firms become specialist in providing a range of products to a specific segment while other may target several segments of the same market with even wider product lines.

The main result of the paper may suggest at first an interpretation of the central firm as supplying "general purpose" products; my paper, however, differs in several respects and can be contrasted with the existing literature (Von UngernSternberg, 1988; Hendel and Neiva de Figuereido, 1996; Doraszelski and Draganska, 2006). Firstly, in my model the nature of the product is determined by the customisation allowed by price discrimination rather than lower transport costs (Von Ungern-Sternberg, 1988; Hendel and Neiva de Figuereido, 1996). Secondly, unlike in Von Ungern-Sternberg (1988) and Hendel and Neiva de Figuereido (1996), firms supply product lines rather than individual products; moreover, unlike Doraszelski and Draganska (2006), generally appealing and niche product lines co-exist in equilibrium.

\section{Extensions}

In this section the model is extended in four directions: first, firms can have heterogeneous production cost; second, transport cost are a quadratic function of distance; third, consumers are distributed according to a generic distribution function; fourth, we allow for $n=N+1$ firms to enter the market.

\subsection{Heterogeneous costs}

Suppose firms can be heterogeneous: there is a distribution of unit production costs $c_{i}$ and without loss of generality $c_{1} \leq . . \leq c_{i} \leq . . \leq c_{n}$. The following results can be stated:

Proposition 5 If firms are heterogeneous with respect to the production costs $c_{i}$, the model has the following outcomes:

(i) if $n<N$ and $c_{n}-c_{1} \leq \frac{t}{2}$, the location profile:

$$
y_{i}^{*}=\frac{1}{2} \quad y_{k}^{*}=\frac{1}{6}+\frac{c_{i}-c_{k}}{3 t} \quad \forall k \neq i ;
$$


is the unique equilibrium outcome;

(ii) if $n=N$ and $c_{n}-c_{1} \leq \frac{t}{2}$ :

a. for $n=2,3$ the location profile:

$$
y_{i}=\frac{1}{4}-\frac{(n-1) c_{i}-\sum_{j \neq i} c_{j}}{t(4-n)} \quad y_{k}=\frac{1}{4}+\frac{\sum_{j \neq i} c_{j}-(n-4) c_{k}-3 c_{i}}{3 t(n-4)} \quad \forall k \neq i
$$

is the only equilibrium outcome;

b. for $n=4,5$ both the location profiles (4) and (5) are equilibrium outcomes;

c. for $n \geq 6$ the location profile (4) is the only equilibrium outcome.

Mutatis mutandis, the proposition shows that the results illustrated in Section 3 generalize to the case of heterogeneous costs. In case there are more spokes than firms, there is only one outcome featuring one firm, the most effective in capturing the empty spokes, at the centre of the market. All other firms focus on their market segments; their exact location now depends on the relative efficiency of the firm compared to the one located in the centre. A sufficient condition for this profile to be an equilibrium outcome is that the difference between the highest and lowest cost firms is not too large: this condition is obviously satisfied if firms are homogeneous and guarantees both that all firms make non-negative profits and do not wish to locate outside of their spokes, i.e. $y_{k} \geq 0$. If there are as many firms as market segments and their number is sufficiently high, $n \geq 4$, the same equilibrium outcome as for $n<N$ is obtained. However, if the number of firms and market segments is not too high, $n \leq 5$, there is another equilibrium outcome with all firms choosing a location internal to their market segment. The exact location of firms depends now on the costs of all other firms. This is well illustrated by looking at the best response functions for firm $i$, the most effective in serving consumers on other segments, and firms $k$ :

$$
y_{i}=\frac{1}{t(n-5)}\left[\sum_{j \neq i}\left(c_{i}-c_{j}\right)-t\left(1-\sum_{j \neq i} y_{j}\right)\right] \quad y_{k}=\frac{1}{3 t}\left[\left(c_{i}-c_{k}\right)+t\left(1-y_{i}\right)\right]
$$

Firms $k$ 's best response depends only on its own cost and the cost of firm $i$; however, firm $i$ 's best response depends on the costs of all firms on the market: hence, in equilibrium, the location of both types of firms depends on the whole distribution of production $\operatorname{costs} c_{i}$. The results obtained are comparable with spatial price discrimination in the circular city framework. Vogel (2011) finds that more efficient firms 
tend to locate more distantly. In the spokes model, price discrimination leads to less clear cut results. If $n=N$ and the number of firms is low enough then the outcome features all firms locating inside their own market segment $(n=2,3)$ : in that case, more efficient firms locate closer to the centre and, consequently, closer to each other (i.e. $\left.\frac{d y_{i}}{d c_{i}}<0, \frac{d y_{k}}{d c_{k}}<0\right)$. As the number of firms increases, there are two outcomes and the results on the impact of efficiency on optimal location are mixed. In the equilibrium outcome where all firms locate at the interior of their spoke, locations are insensitive to variations in the cost if $n=4$ (i.e. $\frac{d y_{i}}{d c_{i}}=0, \frac{d y_{k}}{d c_{k}}=0$ ); if $n=5$, firm $i$ is serving consumers on other spokes: if more efficient, it can maintain its advantage even locating further away from the centre, so $\frac{d y_{i}}{d c_{i}}>0$. In the outcome where one of the firms locates in the centre (holding also for $n<N$ ), clearly $\frac{d y_{i}}{d c_{i}}=0$; all other firms, the more efficient the closer they locate $\left(\frac{d y_{k}}{d c_{k}}<0\right)$.

Finally, as the results of Proposition 1 and 2 extend to the case of heterogeneous firms, the optimal location configurations locally minimise the social cost, although not necessarily globally. An implication of the finding is that only one of the $n$ location profiles in which one firm locates in the centre is globally minimising social cost: this is clearly the profile in which the lowest cost firm locates at the centre. Notice that this would be also the location profile selected by a monopolist owning all plants.

\subsection{Quadratic transport costs}

The disutility of adapting the product to consumers (transport cost) has been assumed to be linear throughout the paper; suppose instead it is proportional to the square of the distance, i.e. denoting the total disutility as $T_{i s}$ :

$$
T_{i s}\left(y_{i}, x_{s}\right)=\left\{\begin{array}{cl}
t d^{2}\left(y_{i}, x_{s}\right)=t\left(y_{i}-x_{s}\right)^{2} & s=i \\
t d^{2}\left(y_{i}, x_{s}\right)=t\left(1-y_{i}-x_{s}\right)^{2} & \forall s \neq i
\end{array}\right.
$$

depending on whether the consumer is on the same spoke as firm $i$ or on a different spoke $s$. Notice that under the new specification of transport costs, the results of Proposition 1 and 2 keep holding. One implication is that the optimal locations eventually devised in this case are also (locally) minimising social cost. Optimal locations are identified in the following proposition:

Proposition 6 If transport costs are proportional to the square of the distance, the model has the following outcomes: (i) if $n<N$ the unique equilibrium location profile 
is:

$$
y_{i}=\frac{1}{2}, \quad y_{k}=\frac{1}{6} \quad \forall k \neq i
$$

(ii) if $n=N$ : $a$. for $n=2,3$ and $6 \leq n \leq 10$ the location configuration:

$$
y_{i}=3 \frac{\sqrt{n^{2}-8 n+16}-3 n}{16(n-1)}+1, \quad y_{k}=\frac{3 n-\sqrt{n^{2}-8 n+16}}{16(n-1)}, \quad \forall k \neq i
$$

is the equilibrium outcome; $b$. for $n=4,5$, both (6) and the configuration

$$
y_{i}=\frac{1}{4}, \quad \forall i=1 . . n
$$

are equilibrium outcomes; $c$. for $n>10$, the location configuration $y_{i}=\frac{1}{2}, y_{k}=\frac{1}{6}$ is the equilibrium outcome.

Optimal location is quite robust to the specification of transport cost. In case not all market segments are occupied by firms, $n<N$, the equilibrium location configuration is unaffected: the appeal of profits on a large segment of the market always leads one firm to choose the central location. In case there are as many firms as spokes, for intermediate values of $n$ there are once again two equilibrium outcomes: multiplicity, however, happens only if $n=5 .{ }^{6}$ For $n=5$, quadratic transport costs imply that both in the symmetric and the asymmetric outcomes, the location of all firms is internal to their spokes. As the number of firms and spokes increases only the asymmetric outcome is left. If $n \geq 10$ the corner solution equilibrium, in which one firm chooses the central location, is finally reached. Quadratic transport costs reduce the incentive to move towards the centre of the market: the profit margins are reduced compared to the linear cost case so that the gains of stealing consumers from rivals needs to be sufficiently important (i.e. multiplied by a large $n-1$ ). Finally, multiplicity for $n=5$ implies that the two outcomes can be compared in terms of the social cost: as in the linear transport cost case, the asymmetric outcome is the one that globally minimises the social cost.

\subsection{More general distribution}

Suppose transport cost are once more linear; the assumption of uniformly distributed consumers over spokes is instead relaxed. If a more general distribution over the spokes, $f(x)$, is assumed, the following result can be stated:

\footnotetext{
${ }^{6}$ If $n=4$, the two location configurations coincide and $y_{i}=\frac{1}{4}$ for all firms $i$.
} 
Proposition 7 Suppose consumers are distributed over spokes according to the distribution function $f(x)$ :

(i) if $n=N$ the model has the following equilibrium outcomes:

a) if $y_{i}=y, i=1 . . n$, the optimal location configuration satisfies:

$$
F\left(y_{i}\right)=\frac{1}{2 n} \quad \forall i=1 . . n
$$

and $2 f\left(y_{i}\right) \geq f\left(\frac{1}{2}\right)$;

b) if $y_{i}>y_{k}, k \neq i$, the optimal location configuration satisfies either:

1 .

$$
\begin{aligned}
F\left(y_{i}\right) & =\frac{1}{2}-(n-1) F\left(y_{k}\right), \\
F\left(y_{k}\right) & =\frac{1}{2} F\left(\frac{1-y_{i}+y_{k}}{2}\right), \quad y_{i}, y_{k} \in[0,1 / 2]
\end{aligned}
$$

Moreover, $4 f\left(y_{i}\right) \geq(n-1) f\left(\frac{1-y_{i}+y_{k}}{2}\right)$ and $4 f\left(y_{k}\right) \geq f\left(\frac{1-y_{i}+y_{k}}{2}\right)$ hold for $i$ and all $k \neq i$

or: 2.

$$
\begin{aligned}
y_{i} & =\frac{1}{2} \\
F\left(y_{k}\right) & =\frac{1}{2} F\left(\frac{1+2 y_{k}}{4}\right)
\end{aligned}
$$

and $4 f\left(y_{k}\right) \geq f\left(\frac{1+2 y_{k}}{4}\right)$ for all $k \neq i$;

(ii) if $n<N$ the model has outcomes as in point b) of part (i).

The results obtained under uniform distribution are, once again, quite robust. Two outcomes are possible depending on whether one firm occupies the central spot or all firms locate in the interior of their spokes. The second order conditions in this case require that the density of consumers indifferent between firm $i$ and other firms $k$ is not too large. The optimal locations clearly depend on the specific distribution; however, the properties of the equilibrium outcomes are not affected. Notice further that if the location profile is symmetric and $n=N$ (case a), all firms locate in correspondence of the median of the distribution, $F(y)=\frac{1}{2 n}$. The results in Proposition 1 and 2 still hold under the new assumption and the relation between profit maximising locations and social cost keeps holding.

Loertscher and Muehlheusser (2011) show how the shape of the distribution affects not only the location but also the properties of the equilibrium outcomes. Their work, 
however, differs from this in two major respects: first, they focus on a sequential entry game; secondly and more importantly, they consider location on a linear segment rather than on a multi-segmented market structure as the spokes model.

\section{4 $N+1$ firms on the market}

Chen and Riordan (2007a) restrict their attention to firms not exceeding in number the spokes/market segments. However, it can not be a priori excluded that more than one firm may want to enter and locate on each segment of the market, i.e. $n>N$. The complete analysis of the general case is beyond the scopes of this paper; the special case in which $n=N+1$, however, is addressed and the following result can be stated:

Proposition 8 Suppose $n=N+1$ firms enter the market and two firms share the same spoke. The equilibrium location configuration is:

$$
y_{l}^{*}=\frac{1}{2} \quad y_{k}^{*}=\frac{1}{6} \quad \forall k=1 \ldots N .
$$

The intuition for the result is the following. If two firms share spoke $i$, one of them locates at the centre of the market to maximise the distance from the other firm on the same spoke; at the same time, it attracts consumers from all other spokes. Given there is a firm at the centre, all other firms focus on their respective segments and locate optimally within their own spoke at $\frac{1}{6}$. The optimal location outcome is similar to the asymmetric ones arising in the $n<N$ and the $n=N$ cases: the only difference is that now all spokes feature one firm located at its interior. Notice that the result is consistent with the locations found in the three firms unit line case $(n=2)$. This equilibrium outcome is also interesting as it would occur in presence of free entry provided that: 1) entry costs are identical for all firms, 2) entry cost are not too high, so more than one firm can enter, 3) entry cost are not too low, so that no more than $N+1$ firms enter the market. Finally, De Palma et al. (1987) find an equilibrium with similar properties in a three firms location game on the Hotelling line; their results hinge on the fact that consumers not necessarily choose to buy from the nearest firm or firms are not fully informed about consumers locations and motivations to buy. 


\section{Conclusions}

This paper analyses location/product line choices of firms in the spokes model. The spokes model provides an ideal approach to spatial non-localised competition, i.e. markets characterized by several segments in which neighbouring effects are not extremely relevant. The analysis sheds light on the effects of price discrimination and, consequently, product lines of targeted products. The results suggest that firms' location choices are related to the competitiveness of the market. As the number of firms increases, outcomes characterized by large asymmetries in location arise: in particular, one firm supplies a product line that is appealing to all segments of the market; other competitors, instead, supply specialised product lines that target a specific segment of the market. These product line patterns are observed in many markets constituted of different segments as, for example, software, sports equipment, retail chains. A further interesting result regards the properties of the equilibrium outcomes: in a moderately competitive market structure, multiplicity of equilibrium location patterns arise; this implies that the location configuration may not be globally minimising the overall transport costs to serve the market.

The analysis conducted leaves open some interesting questions. First, under the assumptions made, only one firm supplies a generally appealing product line. One direction for further research is to establish conditions under which two or more firms opt for a product line that attracts consumers from several segments while others specialize on a more restricted segments. A second question is how product lines under uniform non-discriminatory pricing compare with price discrimination. As in the Hotelling setting (D'Aspremont et al., 1979), the uniform pricing case may involve non-negligible technical challenges and may be solvable only under specific assumptions (e.g. non-linear transport costs). Finally, Spulber $(1984,1989)$ shows how firms may employ non-linear pricing and quantity discounts to induce consumers to reveal information on their location. Hence, an interesting question is how incomplete information on consumers' tastes affects firms' pricing and product line decisions in the spokes model. 


\section{References}

[1] Anderson S.P. and A. De Palma (1988), "Spatial Price Discrimination with Heterogeneous Products", Review of Economic Studies , vol.55(4), 573-592.

[2] Caminal R. (2010), "Markets and linguistic diversity", Journal of Economic Behavior \& Organization, vol. 76(3), 774-790.

[3] Caminal R. and A. Claici (2007), "Are Loyalty Rewarding Schemes Anti-Competitive?", International Journal of Industrial Organization, vol. 25(4), 657-674.

[4] Caminal R. and L.M. Granero (2012), "Multi-product firms and Product Variety", Economica, vol. 79, 303-328.

[5] Chen Y. and M. Riordan (2007a), "Price and Variety in the Spokes Model", The Economic Journal, vol. 117, 897-921.

[6] Chen Y. and M. Riordan (2007b), "Vertical Integration, Exclusive Dealing and Ex-Post Cartelization", Rand Journal of Economics, vol.38, 1-21.

[7] D'Aspremont C., Gabszewicz J.J. and J.F. Thisse (1979), "On Hotelling's "Stability in Competition"", Econometrica, vol.47 (5), 1145-1150.

[8] De Palma A., Ginsburgh V. and J.F. Thisse (1987), "On exsistence of location equilibria in the 3-firm Hotelling problem", Journal of Industrial Economics, vol. XXXVI (2), 245252.

[9] Doraszelski U. and M. Draganska (2006), "Market Segmentation Strategies of Multiproduct Firms", Journal of Industrial Economics, vol. 53, 125-149.

[10] Ganuza J.J. and E. Hauk (2005), "Allocating Ideas: Horizontal Competition in Tournaments", Economics Working Papers 594, Universitat Pompeu Fabra.

[11] Germano F. (2009), "On commercial media bias", Economics Working Papers 1133, Universitat Pompeu Fabra

[12] Germano F. and Meier (2010), "Concentration and self-censorship in commercial media," Economics Working Papers 1256, Universitat Pompeu Fabra.

[13] Gupta B. (1992), "Sequential Entry and Deterrence with Competitive Spatial Price Discrimination", Economic Letters, vol.38, 487-490. 
[14] Hendel I. and J. Neiva de Figuereido (1997), "Product Differentiation and Endogenous Disutility", International Journal of Industrial Organization, vol. 16, 63-79.

[15] Hotelling H. (1929), "Stability in Competition", Economic Journal, vol.39, 41-57.

[16] Kats A. (1987), "Location-Price Equilibria in a Spatial Model of Discriminatory Pricing", Economics Letters, vol. 25, 105-109.

[17] Konrad K.A. (2000), "Spatial Contests", International Journal of Industrial Organization, vol.18, 965-974.

[18] Lederer P. and A.P. Hurter (1986), "Competition of Firms: Discriminatory Pricing and Location", Econometrica, vol.54, 623-640.

[19] Lerner A. and H. Singer (1937), "Some Notes on Duopoly and Spatial Competition", Journal of Political Economy, vol. 45(2), 145-186.

[20] Loertscher S. and G. Muehlheusser (2011), "Sequential Location Games", Rand Journal of Economics, vol. 42, 639-663.

[21] MacLeod W.B., Norman G. and J.F. Thisse (1988), "Price Discrimination and Equilibrium in Monopolistic Competition", International Journal of Industrial Organization, vol.6(4), 429-446.

[22] Mantovani A. and F. Ruiz Aliseda (2011), "Equilibrium Innovation Ecosystems: The Dark Side of Collaborating with Complementors", NET Institute Working Paper 11-31.

[23] Salop S.C. (1979), "Monopolistic Competition with Outside Goods", Bell Journal of Economics, vol.10, 141-156.

[24] Spulber D. (1984), "Competition and Multiplant Monopoly with Spatial Nonlinear Pricing", International Economic Review, vol. 25(2), 425-439.

[25] Spulber D. (1989), "Product Variety and Competitive Discounts", Journal of Economic Theory, vol. 48, 510-525.

[26] Thisse J.F. and X. Vives (1988), "On the Strategic Choice of Spatial Price Policy", American Economic Review, vol.78, 122-137.

[27] Vogel J. (2011), "Spatial Price Discrimination with Heterogeneous Firms", Journal of Industrial Economics, vol. LIX (4), 661-676. 
[28] Von Ungern Sternberg T. (1988), "Monopolistic Competition and General Purpose Products", Review of Economic Studies, vol. 55, 231-246.

\section{A Appendix}

\section{Proof of Proposition 2}

If $y=\left(y_{1}^{*}, . ., y_{i}^{*}, . ., y_{n}^{*}\right)$ is a vector of equilibrium locations, then:

$$
\pi_{i}\left(y_{i}^{*}, p_{i}^{*}, y_{-i}^{*}, p_{-i}^{*}\right) \geq \pi_{i}\left(y_{i}, p_{i}^{*}, y_{-i}^{*}, p_{-i}^{*}\right) \quad \forall y_{i} \in X \quad \forall i=1 \ldots n
$$

which, by (2), can be written as:

$\frac{2}{N} \int_{X} \min \left\{c+t d\left(y_{-i}, x\right)\right\} d x-S C\left(y_{i}^{*}, y_{-i}^{*}\right) \geq \frac{2}{N} \int_{X} \min \left\{c+t d\left(y_{-i}, x\right)\right\} d x-S C\left(y_{i}, y_{-i}^{*}\right)$

from which (3) follows immediately. The vector $y=\left(y_{1}^{*}, . ., y_{i}^{*}, . ., y_{n}^{*}\right)$ is then a pricelocation equilibrium of the spokes model when $n=N$. Q.E.D.

\section{Proof of Proposition 3}

- For point (i) and (ii) consider first outcomes in which firms choose a location internal to their spoke, $y_{i} \in\left[0, \frac{1}{2}[, \forall i=1 . . n\right.$. The profit of a given firm $i$ is:

$$
\begin{aligned}
\pi_{i}= & \frac{2}{n} \int_{0}^{\frac{1}{2}} \min _{\forall j \neq i}\left\{c+t d\left(x, y_{j}\right)\right\}-\left(c+t d\left(x, y_{i}\right)\right) d x+ \\
& +\frac{2}{n} \sum_{\forall j \neq i} \int_{x_{i j}}^{\frac{1}{2}}\left[\min _{\forall j \neq i}\left\{c+t d\left(x, y_{j}\right)\right\}-\left(c+t d\left(x, y_{i}\right)\right)\right] d x
\end{aligned}
$$

if $x_{i j}=\frac{1-y_{i}+y_{j}}{2}$ does not lie on firm $i$ 's spoke. Maximising firm $i$ 's profits leads to find $y_{i}^{*}=\frac{1}{4}$. The same outcome is obtained in case $x_{i j}$ lies on firm $i$ 's spoke. Suppose firm $i$ considers a deviation from $\frac{1}{4}$ to a location $\frac{1}{4}+\delta$. In that case, it would get a profit $\pi_{i}^{D}\left(\frac{1}{4}+\delta, \frac{1}{4}, \ldots, \frac{1}{4}\right), 0<|\delta|<\frac{1}{4}$; this is:

$$
\pi_{i}^{D}\left(\frac{1}{4}+\delta, \frac{1}{4}, \ldots, \frac{1}{4}\right)=\frac{1}{8 n}\left(3 t-20 t \delta^{2}+4 n t \delta^{2}\right)
$$


For the deviation to be profitable, the expression:

$$
\pi_{i}^{D}-\pi_{i}^{*}
$$

must have a positive sign. This happens if and only if $t \delta^{2}(4 n-20)>0$, implying there is a possible deviation if and only if $n>5$. Hence, the vector $y_{i}=\frac{1}{4}$, $\forall i=1 \ldots n$ is an equilibrium outcome for $n \leq 5$.

- For point (ii) and (iii) consider asymmetric outcomes. Suppose firm $i$ locates at $y_{i}=\frac{1}{2}$. The profit of a given rival firm $k \neq i$ is:

$$
\pi_{k}=\frac{2}{n} \int_{0}^{x_{k i}}\left[(c+t d(x, 1 / 2))-\left(c+t d\left(x, y_{k}^{*}\right)\right)\right] d x
$$

with $x_{k i}=\frac{1}{4}+\frac{y_{k}}{2}$. Maximising firm $k$ 's profits leads to find $y_{k}^{*}=\frac{1}{6}$. Firm $i$ 's profits are:

$$
\pi_{i}^{*}\left(\frac{1}{2}, y_{k}^{*}\right)=\frac{t}{18 n}(n+5)
$$

Suppose firm $i$ consider a deviation from $\frac{1}{2}$ to a location $\frac{1}{2}-\delta$. In that case, it would get a profit $\pi_{i}^{D}\left(\frac{1}{2}-\delta, \frac{1}{6}\right), 0<\delta<\frac{1}{2}$; this is:

$$
\pi_{i}^{D}\left(\frac{1}{2}-\delta, \frac{1}{6}\right)=\frac{t}{18 n}\left[(9 n-45) \delta^{2}+(24-6 n) \delta+(n+5)\right]
$$

In case the deviation is profitable, the expression:

$$
\pi_{i}^{D}-\pi_{i}^{*}
$$

must have a positive sign. This happens if and only if: $\delta^{2}(9 n-45)-\delta(24-6 n)>$ 0 , implying there is a possible deviation if and only if $n \leq 3$. Hence, the vector $\left(y_{i}=\frac{1}{2}, y_{k}=\frac{1}{6}\right), \forall k \neq i$ is an equilibrium outcome only for $n \geq 4$.

Q.E.D.

\section{Proof of Lemma 1}

Suppose first that the vector of equilibrium locations is $y^{*}=\left(\frac{1}{2}, \ldots, \frac{1}{2}\right)$, i.e. the centre of the market. In this case all firms obtain zero profits, as no one has cost advantage in delivering the product:

$$
c+t d\left(x, y_{i}^{*}\right)=\min \left\{c+t d\left(x, y_{-i}^{*}\right)\right\} \quad \forall x \in X
$$


which is implying that:

$$
p_{i}(x \mid y)=c+t d\left(x, y_{i}^{*}\right) \quad \forall x \in X
$$

so that $\pi_{i}=0 \forall i=1 . . n$. However, this implies that each firm has a unilateral incentive to deviate from $y_{i}^{*}=\frac{1}{2}$ and choose an internal location on its spoke $y_{i} \in\left[0, \frac{1}{2}[\right.$. If the deviation is $\delta>0$, then:

$$
c+t d\left(x, y_{i}^{*}-\delta\right)<\min _{\forall j \neq i}\left\{c+t d\left(x, y_{j}^{*}\right)\right\} \quad \forall x \in D_{i}
$$

where $D_{i}$, the market served by firm $i$, is now constituted by consumers on its own spoke with a location such that $i$ faces the lowest cost in delivering to them, i.e. $D_{i}=\left\{x \in X_{i} \mid x \in\left[0, \frac{1}{2}-\frac{\delta}{2}\right]\right\}$. This implies that firm $i$ makes a positive mark-up on the market served and has a strictly positive profit:

$$
\pi_{i}=\frac{2}{N} \int_{D_{i}}\left[\min _{\forall j \neq i}\left\{c+t d\left(x, y_{j}^{*}\right)\right\}-\left(c+t d\left(x, y_{i}^{*}-\delta\right)\right)\right] d x>0
$$

This proves that firms have a unilateral incentive to deviate, so the location profile can not be part of an equilibrium. Then $y^{*}=\left(\frac{1}{2}, \ldots, \frac{1}{2}\right)$ can not be an equilibrium outcome.

Suppose, then, the equilibrium vector $y^{*}$ is such that $y_{i}^{*} \in\left[0, \frac{1}{2}[\forall i=1 . . n\right.$. The profits received by firms are:

$$
\pi_{i}\left(y^{*}\right)=\frac{2}{N} \int_{0}^{\frac{1}{2}}\left[\min _{\forall j \neq i}\left\{c+t d\left(x, y_{j}^{*}\right)\right\}-\left(c+t d\left(x, y_{i}^{*}\right)\right)\right] d x
$$

Suppose firm $i$ moves in the direction of the centre of the market by $\delta>0$. In that case the profits of firm $i$ are:

$$
\pi_{i}\left(y_{i}^{*}+\delta, y_{-i}^{*}\right)=\frac{2}{N} \int_{D_{i}}\left[\min _{\forall j \neq i}\left\{c+t d\left(x, y_{j}^{*}\right)\right\}-\left(c+t d\left(x, y_{i}^{*}+\delta\right)\right)\right] d x
$$

which can be re-expressed as:

$$
\begin{gathered}
\pi_{i}\left(y_{i}^{*}+\delta, y_{-i}^{*}\right)=\frac{2}{N} \int_{0}^{\frac{1}{2}}\left[\min _{\forall j \neq i}\left\{c+t d\left(x, y_{j}^{*}\right)\right\}-\left(c+t d\left(x, y_{i}^{*}+\delta\right)\right)\right] d x+ \\
+\frac{2}{N}(N-n) \int_{0}^{\frac{1}{2}}\left[\min _{\forall j \neq i}\left\{c+t d\left(x, y_{j}^{*}\right)\right\}-\left(c+t d\left(x, y_{i}^{*}+\delta\right)\right)\right] d x+ \\
+\frac{2}{N}(n-1) \int_{\frac{1}{2}-\frac{\delta}{2}}^{\frac{1}{2}}\left[\min _{\forall j \neq i}\left\{c+t d\left(x, y_{j}^{*}\right)\right\}-\left(c+t d\left(x, y_{i}^{*}+\delta\right)\right)\right] d x
\end{gathered}
$$


The profit differential then is:

$$
\Delta \pi_{i}\left(y^{*}, \delta\right)=\pi_{i}\left(y_{i}^{*}+\delta, y_{-i}^{*}\right)-\pi_{i}\left(y^{*}\right)
$$

Substituting the expressions for distance and after simplification it is found:

$$
\Delta \pi_{i}\left(y^{*}, \delta\right)=\pi_{i}\left(y_{i}^{*}+\delta, y_{-i}^{*}\right)-\pi_{i}\left(y^{*}\right)=\frac{1}{2 N} t \delta\left[8 y_{i}^{*}-2+2(N-n)+\delta(n-1)\right]
$$

As $N-n>0$ and $n-1 \geq 0$ it follows that $\Delta \pi_{i}\left(y^{*}, \delta\right)>0 \forall y^{*} \in\left[0, \frac{1}{2}[\right.$; hence, $\pi_{i}\left(y_{i}^{*}+\delta, y_{-i}^{*}\right)>\pi_{i}\left(y^{*}\right)$ and firms have a unilateral incentive to deviate from $y^{*}$. Q.E.D.

\section{Proof of Proposition 4}

Suppose first that the equilibrium configuration is $y_{i}=\frac{1}{2}$ for two or more firms $i$; in this case, all firms $i$ obtain zero profits. For the firm at the centre to have positive profits, it must be the only one to choose $y_{i}=\frac{1}{2}$; all other firms choose a location belonging to the interior of their spoke. The problem faced by firms then is:

$$
\begin{gathered}
\max _{y_{k}} \pi_{k}\left(y_{k}, y_{i}\right)=\frac{2}{N} \int_{0}^{x_{i k}}\left[\left(c+t d\left(y_{i}, x\right)\right)-\left(c+t d\left(y_{k}, x\right)\right)\right] d x \quad y_{i}, y_{k} \in\left[0, \frac{1}{2}\right] \\
\max _{y_{i}} \pi_{i}\left(y_{i}, y_{k} . . y_{k}\right)=\frac{2}{N} \int_{0}^{\frac{1}{2}}\left[\min _{\forall j \neq i}\left\{c+t d\left(y_{j}, x\right)\right\}-\left(c+t d\left(y_{i}, x\right)\right)\right] d x+ \\
+\frac{2}{N} \sum_{j \neq i} \int_{x_{i j}}^{\frac{1}{2}}\left[\min _{\forall j \neq i}\left\{c+t d\left(y_{j}, x\right)\right\}-\left(c+t d\left(y_{i}, x\right)\right)\right] d x+ \\
+\frac{2}{N}(N-n) \int_{0}^{\frac{1}{2}}\left[\min _{\forall j \neq i}\left\{c+t d\left(y_{j}, x\right)\right\}-\left(c+t d\left(y_{i}, x\right)\right)\right] d x
\end{gathered}
$$

where:

$$
x_{i j}=\frac{1-y_{i}+y_{j}}{2}
$$

represents the consumer on $j$-th spoke which is indifferent between firm $j$ and firm $i$. Firm $i$ has an incentive to move its location beyond the centre to $y_{i}>\frac{1}{2}$ : under the assumptions $N>n$ and $y_{k} \in\left[0, \frac{1}{2}\right]$,

$$
\left.\frac{\partial \pi_{i}\left(y_{i}, y_{k} . y_{k}\right)}{\partial y_{i}}\right|_{y_{i}=\frac{1}{2}}=\frac{t}{N}\left(\frac{2 N-(n+3)}{2}-(n-1) y_{k}\right)>0
$$


Hence, $y_{i}^{*}=\frac{1}{2}$ is firm $i$ 's optimal choice. Firms $k$ choose their best response to $y_{i}^{*}$, or: $y_{k}^{*}=\frac{1}{6}, \forall k \neq i$. The same location profile is also minimising the social cost. In this case

$$
\begin{gathered}
S C\left(y_{i}, y_{-i}\right)=\frac{2}{N} \sum_{j \neq i} \int_{0}^{x_{i j}}\left(c+t d\left(y_{j}, x\right)\right) d x+\frac{2}{N} \int_{0}^{\frac{1}{2}}\left(c+t d\left(y_{i}, x\right)\right) d x+ \\
+\frac{2}{N}(N-n) \int_{0}^{\frac{1}{2}}\left(c+t d\left(y_{i}, x\right)\right) d x+\frac{2}{N} \sum_{j \neq i} \int_{x_{i j}}^{\frac{1}{2}}\left(c+t d\left(y_{i}, x\right)\right) d x
\end{gathered}
$$

The problem is:

$$
\begin{gathered}
\min _{y_{i}, y_{j}} S C\left(y_{i}, y_{k} . y_{k}\right), \quad k \neq i \\
\text { s.t. } y_{i}, y_{k} \in\left[0, \frac{1}{2}\right]
\end{gathered}
$$

The unconstrained minimization would suggest that firm $i$ should choose location $y_{i}>\frac{1}{2}$ as:

$$
\left.\frac{\partial S C\left(y_{i}, y_{k} . . y_{k}\right)}{\partial y_{i}}\right|_{y_{i}=\frac{1}{2}}=-\frac{t}{N}\left(\frac{2 N-(n+3)}{2}-(n-1) y_{k}\right)<0
$$

holds for all possible $y_{k} \in\left[0, \frac{1}{2}\right]$. Given the constraints, the optimal choice is then $y_{i}^{*}=\frac{1}{2}$; the problem for firm $k$ has an internal solution given by $y_{k}^{*}=\frac{1}{6}, \forall k \neq i$. Q.E.D.

\section{Proof of Proposition 5}

(i) Similar steps as in Proposition 4 are followed. Suppose without loss of generality that firm $i$ is the most effective in attracting consumers from other spokes; the problem can be written as:

$$
\begin{gathered}
\max _{y_{k}} \pi_{k}\left(y_{k}, y_{-k}\right)=\frac{2}{N} \int_{0}^{x_{i k}}\left[\left(c_{i}+t d\left(y_{i}, x\right)\right)-\left(c_{k}+d\left(y_{k}, x\right)\right)\right] d x \quad y_{i}, y_{k} \in\left[0, \frac{1}{2}\right] \\
\max _{y_{i}} \pi_{i}\left(y_{i}, y_{-i}\right)=\frac{2}{N} \int_{0}^{\frac{1}{2}}\left[\min _{\forall j \neq i}\left\{c_{j}+t d\left(y_{j}, x\right)\right\}-\left(c_{i}+t d\left(y_{i}, x\right)\right)\right] d x+ \\
+\frac{2}{N} \sum_{j \neq i} \int_{x_{i j}}^{\frac{1}{2}}\left[\min _{\forall j \neq i}\left\{c_{j}+t d\left(y_{j}, x\right)\right\}-\left(c_{i}+t d\left(y_{i}, x\right)\right)\right] d x+ \\
+\frac{2}{N}(N-n) \int_{0}^{\frac{1}{2}}\left[\min _{\forall j \neq i}\left\{c_{j}+t d\left(y_{j}, x\right)\right\}-\left(c_{i}+t d\left(y_{i}, x\right)\right)\right] d x
\end{gathered}
$$


where $x_{i j}=\frac{c_{i}-c_{j}}{2 t}+\frac{1-y_{i}+y_{j}}{2}, j \neq i$. Firm $i$ would have an incentive to extend its location beyond $\frac{1}{2}$ as:

$$
\left.\frac{\partial \pi_{i}\left(y_{i}, y_{-i}\right)}{\partial y_{i}}\right|_{y_{i}=\frac{1}{2}}=\frac{t}{N}\left(\frac{2 N-3(n+1)}{2}+\sum_{j \neq i} \frac{c_{j}-c_{i}}{t}-\sum_{j \neq i} y_{j}\right)>0
$$

hence, its optimal choice is $y_{i}^{*}=\frac{1}{2}$. Firms $k$ choose their best responses: $y_{k}^{*}=\frac{1}{6}+\frac{c_{i}-c_{k}}{3 t}$, $\forall k \neq i$. At the candidate equilibrium outcome $\left(y_{i}^{*}=\frac{1}{2}, y_{k}^{*}=\frac{1}{6}+\frac{c_{i}-c_{k}}{3 t}\right)$ and under the stated assumptions, (8) holds. Firms $k$ achieve non-negative profits and locate within the allowed boundaries if and only if $c_{k}-c_{i} \leq \frac{t}{2}$; hence, a sufficient condition for this equilibrium to exist is: $c_{n}-c_{1} \leq \frac{t}{2}$.

(ii) The same outcome as in point (i) is also an equilibrium in this case. Setting $n=N$ in part (i), in that case the requirement is:

$$
\left.\frac{\partial \pi_{i}\left(y_{i}, y_{-i}\right)}{\partial y_{i}}\right|_{y_{i}=\frac{1}{2}}=\frac{t}{N}\left((n-3)+\sum_{j \neq i} \frac{c_{j}-c_{i}}{t}-\sum_{j \neq i} y_{j}\right)>0
$$

which is surely satisfied for $n \geq 4$. For the second location profile, the profit function can now be written as:

$$
\begin{aligned}
\pi_{i}= & \frac{2}{N} \int_{0}^{\frac{1}{2}}\left[\min _{\forall j \neq i}\left\{c_{j}+t d\left(x, y_{j}\right)\right\}-\left(c_{i}+t d\left(x, y_{i}\right)\right)\right] d x+ \\
& +\frac{2}{N} \sum_{\forall j \neq i} \int_{x_{i j}}^{\frac{1}{2}}\left[\min _{\forall j \neq i}\left\{c_{j}+t d\left(x, y_{j}\right)\right\}-\left(c_{i}+t d\left(x, y_{i}\right)\right)\right] d x
\end{aligned}
$$

where $x_{i j}=\frac{c_{i}-c_{j}}{2 t}+\frac{1-y_{i}+y_{j}}{2}$ does not lie on firm $i$ 's spoke. For one of all other firms $k$ :

$$
\pi_{k}=\frac{2}{N} \int_{0}^{x_{j i}}\left[\left(c_{i}+t d\left(x, y_{i}\right)\right)-\left(c_{k}+t d\left(x, y_{k}\right)\right)\right] d x
$$

From the first order conditions, the best response functions for firm $i$ and firm $k$ are, respectively:

$$
y_{i}=\frac{1}{t(n-5)}\left(t \sum_{j \neq i} y_{j}+\sum_{j \neq i}\left(c_{i}-c_{j}\right)-t\right) \quad y_{k}=\frac{1}{3 t}\left(t+c_{i}-c_{k}-t y_{i}\right) \quad \forall k \neq i
$$

Solving the system leads to the equilibrium locations reported in the proposition. From the second order conditions, it can be verified that this outcome holds if and only if $n \leq 5$. 
Q.E.D.

\section{Proof of Proposition 6}

Suppose firm $i$ is the most effective in serving other segments of the market; the problem can then be written as:

$$
\begin{aligned}
& \max _{y_{i}} \pi_{i}\left(y_{i}, y_{-i}\right)= \frac{2}{N} \int_{0}^{\frac{1}{2}}\left[\min _{j \neq i}\left\{c+T\left(y_{j}, x\right)\right\}-\left(c+T\left(y_{i}, x\right)\right)\right] d x+ \\
&+\frac{2}{N} \sum_{j \neq i} \int_{x_{i j}}^{\frac{1}{2}}\left[\min _{j \neq i}\left\{c+T\left(y_{j}, x\right)\right\}-\left(c+T\left(y_{i}, x\right)\right)\right] d x+ \\
&+\frac{2}{N}(N-n) \int_{0}^{\frac{1}{2}}\left[\min _{j \neq i}\left\{c+T\left(y_{j}, x\right)\right\}-\left(c+T\left(y_{i}, x\right)\right)\right] d x \\
& \max _{y_{k}} \pi_{k}\left(y_{k}, y_{-k}\right)=\frac{2}{N} \int_{0}^{x_{k i}}\left[\left(c+T\left(y_{i}, x\right)\right)-\left(c+T\left(y_{k}, x\right)\right)\right] d x \quad y_{i}, y_{k} \in\left[0, \frac{1}{2}\right]
\end{aligned}
$$

with $x_{i j}=\frac{1-y_{i}+y_{j}}{2}$. Solving the first order conditions:

$$
\begin{aligned}
& \frac{\partial \pi_{i}}{\partial y_{i}}=-\frac{t}{2 N}\left(\left(3 y_{i}^{2}-y_{k}^{2}-2 y_{i} y_{k}-6 y_{i}+2 y_{k}+1\right)(n-1)+4 N y_{i}-3 N+2 n\right)=0 \\
& \frac{\partial \pi_{k}}{\partial y_{k}}=-\frac{t}{2 N}\left(3 y_{k}^{2}-y_{i}^{2}-2 y_{i} y_{k}+2 y_{i}+2 y_{k}-1\right)=0 \quad \forall k \neq i
\end{aligned}
$$

leads to three candidate location profiles:

$$
\begin{aligned}
\text { (a) } y_{i} & =-\frac{3}{16 n-16}\left(3 N+\sqrt{8 N-16 n-8 N n+9 N^{2}+16}\right)+1, \\
y_{k} & =\frac{1}{16 n-16}\left(3 N+\sqrt{8 N-16 n-8 N n+9 N^{2}+16}\right) \\
\text { (b) } y_{i} & =\frac{3}{16 n-16}\left(-3 N+\sqrt{8 N-16 n-8 N n+9 N^{2}+16}\right)+1, \\
y_{k} & =-\frac{1}{16 n-16}\left(-3 N+\sqrt{8 N-16 n-8 N n+9 N^{2}+16}\right) \\
\text { (c) } y_{i} & =\frac{1}{4 N}(3 N-2), \quad y_{k}=-\frac{1}{4 N}(N+2)
\end{aligned}
$$

The candidate solutions must satisfy the second order conditions:

$$
\frac{\partial^{2} \pi_{i}}{\partial y_{i}^{2}} \leq 0, \quad \frac{\partial^{2} \pi_{k}}{\partial y_{k}^{2}} \leq 0 \quad \forall k \neq i
$$


and the constraint $y_{i}, y_{k} \in\left[0, \frac{1}{2}\right]$. Candidate (c) never satisfies (9). In case $n<N$, candidate (b) is the only solution and it always satisfies (9). In case $n=N$, candidate (a) implies $y_{i}=\frac{1}{4}$ for all firms $i$ and it satisfies (9) only for $n=4,5$. Candidate (b) satisfies (9) for all possible values of $n$; for $n \geq 10$ the candidate solution does not respect the requirement that $y_{i}, y_{k} \in\left[0, \frac{1}{2}\right]$ : the corner solution $y_{i}=\frac{1}{2}$ and $y_{k}=\frac{1}{6}$ then is the equilibrium outcome.

Q.E.D.

\section{Proof of Proposition 7}

Using the standard notation, the problem faced by firms can be written as:

$$
\begin{gathered}
\max _{y_{i}} \pi_{i}\left(y_{i}, y_{-i}\right)=\frac{2}{N} \int_{0}^{\frac{1}{2}}\left[\min _{\forall j \neq i}\left\{c+t d\left(y_{j}, x\right)\right\}-\left(c+t d\left(y_{i}, x\right)\right)\right] f(x) d x+ \\
+\frac{2}{N} \sum_{j \neq i} \int_{x_{i j}}^{\frac{1}{2}}\left[\min _{\forall j \neq i}\left\{c+t d\left(y_{j}, x\right)\right\}-\left(c+t d\left(y_{i}, x\right)\right)\right] f(x) d x+ \\
+\frac{2}{N}(N-n) \int_{0}^{\frac{1}{2}}\left[\min _{\forall j \neq i}\left\{c+t d\left(y_{j}, x\right)\right\}-\left(c+t d\left(y_{i}, x\right)\right)\right] f(x) d x \\
\max _{y_{k}} \pi_{k}\left(y_{k}, y_{-k}\right)=\frac{2}{N} \int_{0}^{x_{i k}}\left[\left(c+t d\left(y_{i}, x\right)\right)-\left(c+t d\left(y_{k}, x\right)\right)\right] f(x) d x \quad y_{i}, y_{k} \in\left[0, \frac{1}{2}\right]
\end{gathered}
$$

The first order conditions can be written as:

$$
\begin{aligned}
\frac{\partial \pi_{i}}{\partial y_{i}} & =F\left(\frac{1}{2}\right)-2 F\left(y_{i}\right)-(n-1) F\left(\frac{1-y_{i}+y_{k}}{2}\right)+(n-1) F\left(\frac{1}{2}\right)+(N-n) F\left(\frac{1}{2}\right)=0 \\
\frac{\partial \pi_{k}}{\partial y_{k}} & =F\left(\frac{1-y_{i}+y_{k}}{2}\right)-2 F\left(y_{k}\right)=0
\end{aligned}
$$

(i) Consider first the case $n=N$. a) If firms locate symmetrically, both first order condition can be rewritten to identify $y$ as:

$$
F\left(y_{i}\right)=\frac{1}{2 n}
$$

The second order condition requires:

$$
2 f\left(y_{i}\right) \geq f\left(\frac{1}{2}\right)
$$

b) 1 . If firms locate asymmetrically and $y_{i}>y_{k}$ then the solutions are implicitly 
identified by

$$
\begin{aligned}
F\left(y_{i}\right) & =\frac{1}{2}-(n-1) F\left(y_{k}\right), \\
F\left(y_{k}\right) & =\frac{1}{2} F\left(\frac{1-y_{i}+y_{k}}{2}\right) .
\end{aligned}
$$

The second order conditions require:

$$
\begin{aligned}
& 4 f\left(y_{i}\right) \geq(n-1) f\left(\frac{1-y_{i}+y_{k}}{2}\right), \\
& 4 f\left(y_{k}\right) \geq f\left(\frac{1-y_{i}+y_{k}}{2}\right)
\end{aligned}
$$

Finally, the candidate solutions shall respect the constraint $y_{i}, y_{k} \in\left[0, \frac{1}{2}\right]$.

2. If the latter requirement is not satisfied, the corner solution $y_{i}=\frac{1}{2}$ is reached and firms $k$ location will be given by:

$$
F\left(y_{k}\right)=\frac{1}{2} F\left(\frac{1+2 y_{k}}{4}\right),
$$

and the second order condition is: $4 f\left(y_{k}\right) \geq f\left(\frac{1+2 y_{k}}{4}\right)$.

(ii) Consider finally the case $n<N$. It turns out that the first order conditions can be simplified to obtain (10) and (11) and (12) if a corner solution is reached. Hence, the results of b.1) and b.2) apply in this case too.

Q.E.D.

\section{Proof of Proposition 8}

Suppose that firms $i$ and $l$ share spoke $i$; all other firms $k$ locate on their respective spokes. The profit functions are:

$$
\begin{aligned}
\pi_{i} & =\frac{2}{N} \int_{D_{i}}\left[\min _{\forall j \neq i}\left\{c+t d\left(y_{j}, x\right)\right\}-\left(c+t d\left(y_{i}, x\right)\right)\right] d x \\
\pi_{l} & =\frac{2}{N} \int_{D_{l}}\left[\min _{\forall j \neq l}\left\{c+t d\left(y_{j}, x\right)\right\}-\left(c+t d\left(y_{l}, x\right)\right)\right] d x \\
\pi_{k} & =\frac{2}{N} \int_{D_{k}}\left[\min _{\forall j \neq k}\left\{c+t d\left(y_{j}, x\right)\right\}-\left(c+t d\left(y_{k}, x\right)\right)\right] d x
\end{aligned}
$$

Without loss of generality, assume also $y_{i} \leq y_{l}$. The specification of the profit functions depends on which firm is most effective in capturing consumers on other 
segments. No matter which firm is the most effective, it can be shown that no equilibrium with all firms locating strictly within their own spokes is possible: firm $l$ can profitably deviate from any candidate location. Hence, in a candidate equilibrium outcome, one firm is located in the centre.

If one of the $k$ firms, $m$, is located in the centre of the market, firm $l$ still has a profitable deviation at any location as:

$$
\left.\pi_{l}\right|_{y_{m}=\frac{1}{2}}=\left\{\begin{array}{cc}
0 & \text { if } y_{l}=y_{i} \\
\frac{t}{8 N}\left(8 y_{l}^{2}-4 y_{l}+4 y_{i}^{2}-8 y_{i} y_{l}+1\right) & \text { if } \left.y_{l} \in\right] y_{i}, \frac{1}{2}[ \\
0 & \text { if } y_{l}=\frac{1}{2}
\end{array}\right.
$$

does not have a maximum over the support.

The only remaining possibility is that firm $l$ locates at the centre. In that case, the remaining firms' best responses are:

$$
y_{i}=\frac{1}{3} y_{l}, \quad y_{k}=-\frac{1}{3} y_{l}+\frac{1}{3} \quad \forall k \neq i, l
$$

implying they locate at $\frac{1}{6}$ so that the candidate equilibrium vector is: $y^{*}=\left(\frac{1}{2}, \frac{1}{6} \cdots \frac{1}{6}\right)$. Firm $l$ has no incentive to deviate if at location $y_{l}^{\prime}=\frac{1}{2}-\delta, 0<\delta<\frac{1}{3}$, the profit $\pi_{l}^{\prime}$ is not higher than $\pi_{l}^{*}$. This can be evaluated by computing:

$$
\Delta \pi_{l}=\pi_{l}^{*}-\pi_{l}^{\prime}=-\frac{t \delta}{6(n-1)}[3(n-5) \delta-2(n-3)]>0
$$

as $n \geq 3$ and $0<\delta<\frac{1}{3}$. Hence, firm $l$ has no incentive to deviate from the candidate equilibrium outcome. Q.E.D. 